\title{
Effect of Growth Arrestment Disease on the Anatomy and Ultrastructure of Vitis vinifera L. var. sultana
}

\author{
A. C. DE LA HARPE and E. ARCHER \\ Oenological and Viticultural Research Institute, Private Bag X5026, Stellenbosch
}

The authors want to express their thanks and appreciation to:

1. Prof. N. Grobbelaar, head of the Department of Botany, and to the University of Pretoria for making available all facilities used during this study;

2. Dr. J. Coetzee, Department of Botany, University of Stellenbosch, for critically reading this manuscript.

\begin{abstract}
The anatomical and ultrastructural changes caused by the so called Growth Arrestment Disease (G.A.D.) in Vitis vinifera $\mathbf{L}$. var. sultana were investigated by means of scanning and transmitted electron microscopy as well as light microscopy. Important morphological symptoms are described. Anatomical abnormalities were found, especially in the leaves and flower clusters of the affected vines. Heat and moisture stress may induce abnormal physiological changes, and this may give rise to G.A.D.-symptoms.
\end{abstract}

In South Africa, vines of Vitis vinifera L. var. sultana affected by Growth Arrestment Disease (G.A.D.) are restricted to a relatively small viticultural area on the banks of the Orange River in the North Western Cape (Fig. 1). In this area the vines are trellised and irrigated. Climatologically the area is classified as Region V (Winkler, et al. 1974); very hot summers (mean daily temperature $\approx 40{ }^{\circ} \mathrm{C}$ ) as well as cold winters (mean nightly temperature $\approx 2{ }^{\circ} \mathrm{C}$ ) are normal. Soil temperature during late winter/early spring tends to be low (night temperature $\approx 14{ }^{\circ} \mathrm{C}$ ), while the mean day temperature during this period is about $28^{\circ} \mathrm{C}$.

Characteristic symptoms of G.A.D. are arrested shoot growth between budbreak and flowering, flower shatter and conspicuously small leaves (Fig. 2a). In inflorescences in which flower shatter occurs, peduncles and/or pedicels start to darken, and this is usually followed by degeneration of the whole inflorescence (Fig. 2b). G.A.D.-affected plants initially exhibit shiny spots on nearly mature leaves; the spots increase in size, whilst the affected leaves eventually turn dark green (Fig. 3a \& b). After flower shatter normal shoot growth continues. In some cases clusters which have darkened at the peduncle do not shatter, but recover during the season. The economical impact of G.A.D. is due to the direct loss of production following flower shatter, and subsequent abortion of flower bunches.

\section{MATERIALS AND METHODS}

Materials: Peduncles and leaves of G.A.D.-affected as well as visually unaffected vines were sampled for electron and light microscopic studies. In the case of peduncles, the selected material was divided into three categories viz. (i) irreversibly damaged, (ii) self recovered, and (iii) apparently unaffected material. In the case of leaves, the selected material was divided into two categories, i.e. (i) leaves with shiny spots, and (ii) apparently healthy leaves.

Methods: Scanning electron microscopy: (SEM): Leaf material was fixed in FAA and dehydrated with 30, 60,
90 and $100 \%$ acetone. The material was then criticalpoint-dried in carbon dioxide, and sputter coated with gold, after which it was studied with a ISI-100A scanning electron microscope.

Transmitted electron microscopy: (TEM): Peduncles and leaf material were fixed in $4 \%$ glutaraldehyde in $\mathrm{pH} 7,2$ sodium cacodylate buffer $(0,05 \mathrm{M})$, washed in the same buffer, and post fixed in a $2 \%$ osmium tetroxide solution in the same buffer. The material was then dehydrated in a graded acetone series, embedded in Spurr's medium (Spurr, 1969), and ultra thin sections were cut with a Reichert OM U3 ultramicrotome, using glass knives. Sections were contrasted with $4 \%$ uranyl acetate and lead citrate (Reynolds, 1963), and studied with a Philips 301 electron microscope.

Light microscopy: Peduncles and leaf material were prepared as for TEM studies, but $3 \mu \mathrm{m}$ sections were cut with glass knives. Sections were stained with Toluidine blue at $\mathrm{pH} 9,6$.

\section{RESULTS}

In contrast with the normal, turgid epidermal layer of apparently healthy leaves (Fig. 4a \& b), the SEM clearly showed that in affected leaves the adaxial epidermal layer within the shiny spots was collapsed (Fig. 5a). The shiny spots were well defined with a sharp transition between collapsed and normal areas (Fig. 5b).

Light microscopic studies revealed that the leaves of healthy vines were bifacial, with one layer of palisade cells underneath the adaxial epidermis (Fig. 6). On the abaxial side of the leaf, the stomata were at the same level as the other epidermal cells. This agrees with the general structure of $V$. vinifera leaves according to Esau (1953).

It is interesting to note that the collapse of the epidermal cell walls (Fig. 7) coincided with a single layer of palisade cells showing additional paradermally orientated cross walls (Fig. $7 \& 8$ ). In the early collapsed state (small shiny spots), very few palisade cells showed these 


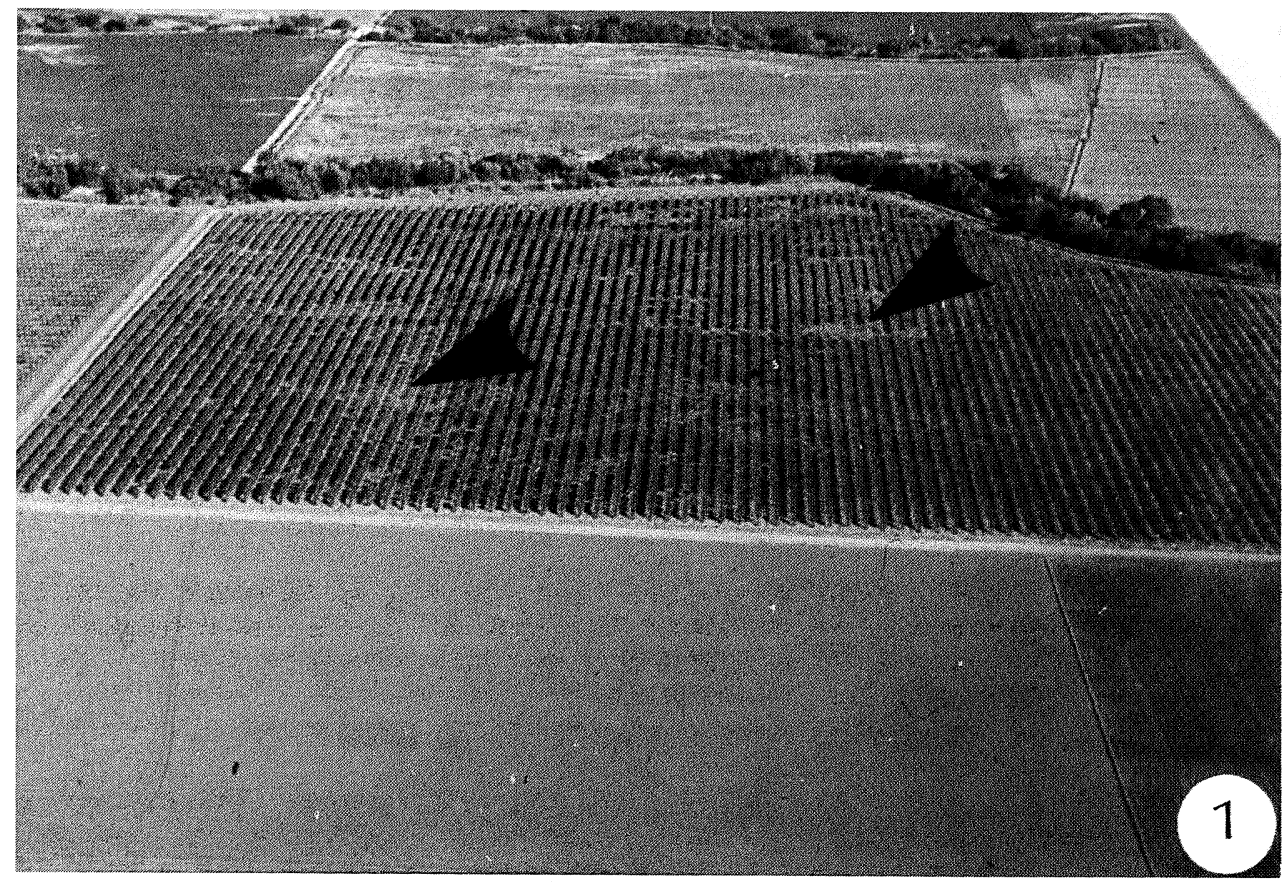

FIG. 1

Typical distribution of G.A.D.-affected vines in a Sultana vineyard.

additional cross walls, while older, more pronounced shiny spots are subtended by palisade cells in which conspicuous cell division had taken place. The result was that more than one palisade "layer" was present in these areas.

In affected leaves the smooth and agranular tannin deposits in the mesophyll cells gradually changed and became granular (Fig. 9). As far as the ultrastructure of G.A.D.-affected leaves was concerned, the cytoplasm as well as the nuclear chromatin were granular. The membranes of cell organelles seemed to be in a process of disintegration. The cells of G.A.D.-affected vines also seemed to be plasmolysed (Fig. 10). Evidently this could not be due to the method of preparation, because the same method was applied to healthy leaves, and these did not plasmolyse.

Where flower shatter occurred, the following changes were apparent: the peduncle hardened, cells plasmolysed, tannins showed a tendency to be displaced to one side of the cell, and a disassociation of periderm cells occurred (Fig. $11 \& 12$ ). The displacement of the tannins was apparently not due to displacement during sectioning, as different cells showed contents which were displaced along different axes. (Fig. 12).

The cells of the peduncle were characterized by a granular appearance. In cases where the clusters darkened at the peduncle but recovered (Fig. 13), the primary xylem was filled with an unknown electron dense substance, whilst the cambium and phloem as well as the distribution of tannins appeared to be normal (Fig. 12). Where the epidermis and cortex were already damaged, the cells of the cortex parenchyma formed a phellogen which, by periclinal divisions, covered the damaged areas (Fig. $11 \& 13$ ). It was interesting to note that although the peduncle tissue recovered, the cytoplasm as well as the nuclear chromatin of cells in neighbouring, undamaged areas maintained a granular appearance (Fig. 14).

\section{DISCUSSION}

It appears that G.A.D.-affected plants may be subject to water stress. Possible evidence for this hypothesis is the plasmolysis of cells as well as the paradermal divisions of the palisade parenchyma. According to Allsopp (1964) a palisade layer consisting of two or more layers, is typical of a plant under water stress (xerophytes). Further support for this hypothesis is supplied by the reports of Kliewer (1975), who found significantly higher arginine and total nitrogen as well as lower CHO concentrations in G.A.D.-affected vines. As far as the arginine is concerned, Barnett \& Naylor (1966) reported higher arginine levels in plants under water stress. These results are confirmed by reports of Rena \& Splittstoesser (1974). The higher arginine concentration and lower CHO concentration are mainly a result of water and/or heat stress (Barnett \& Naylor, 1966; Rena \& Splittstoesser, 1974; Botha, 1978). Because of this stress, abnormal physiological changes may be induced, which may give rise to G.A.D.-symptoms. It is known that cytokinine synthesis is inhibited by low soil temperatures (Salisbury \& Ross, 1978); this causes inhibition of cell division and root growth, which is detrimental to water uptake. The symptoms of G.A.D., therefore, are much like the symptoms of water stress, so that this "disease" may be due to the peculiar climatological attributes of the area in which vines are affected. 


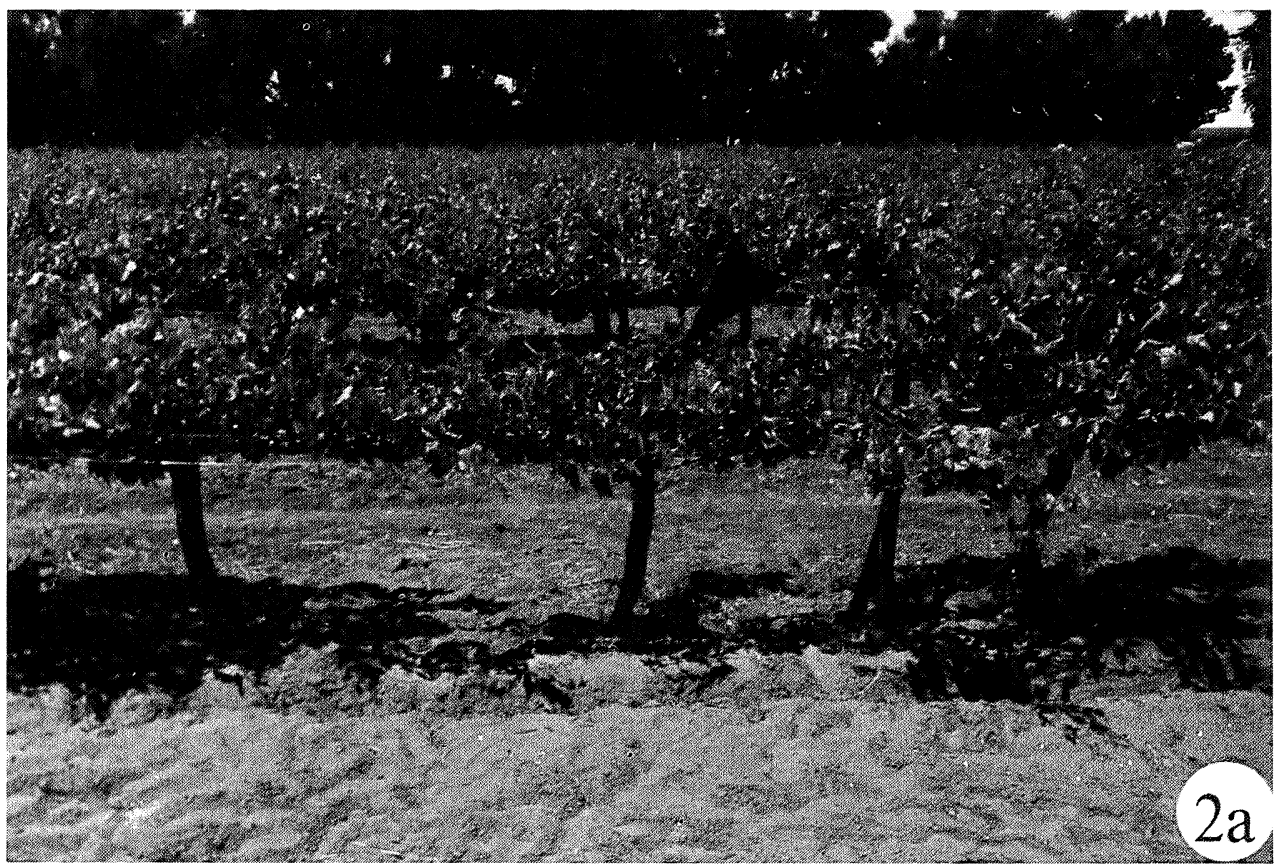

FIG. $2 \mathrm{a}+\mathrm{b}$

G.A.D.-vines showing (2a) the arrestment of shoot growth and (2b) flower shatter on $V$. vinifera var. sultana. (Photos: D. Saayman).

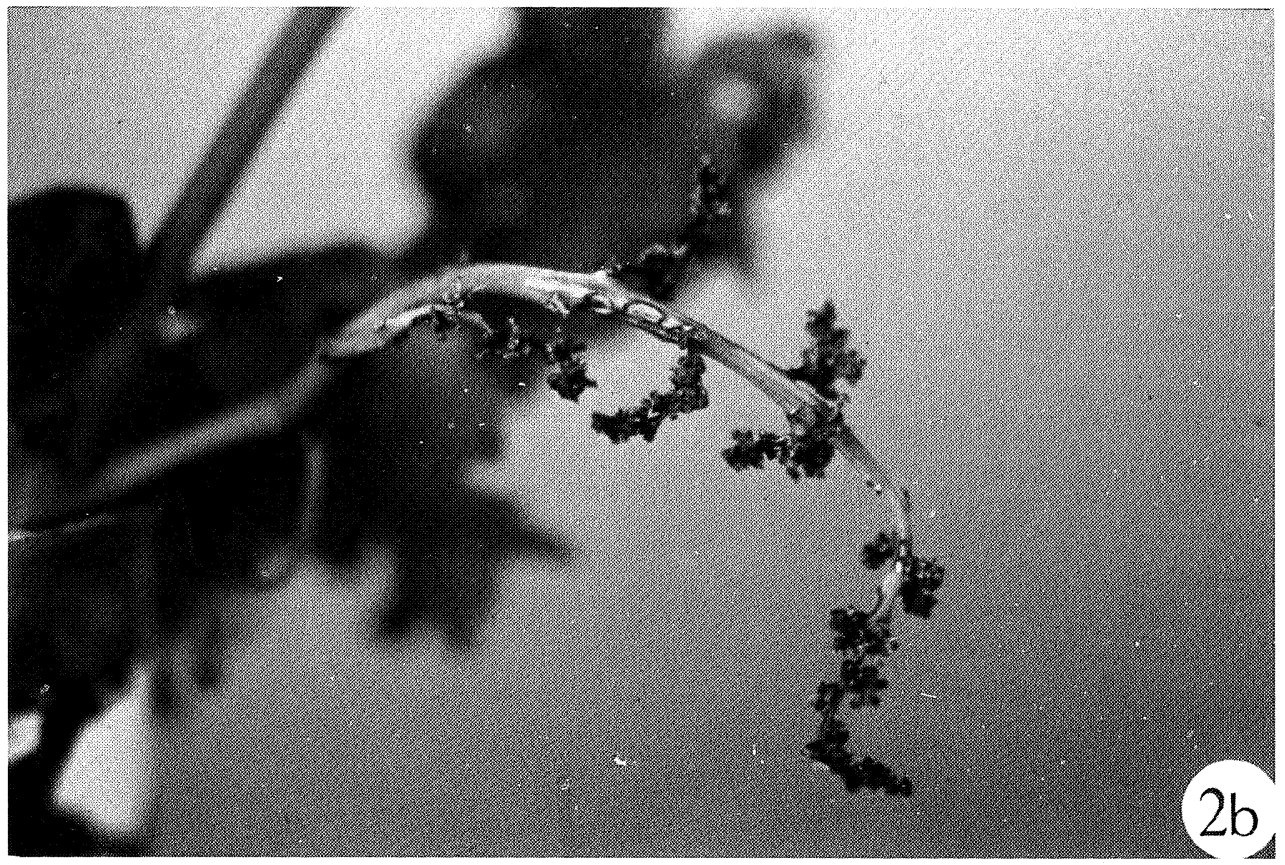

S. Afr. J. Enol. Vitic., Vol. 2. No. 2. 1981 


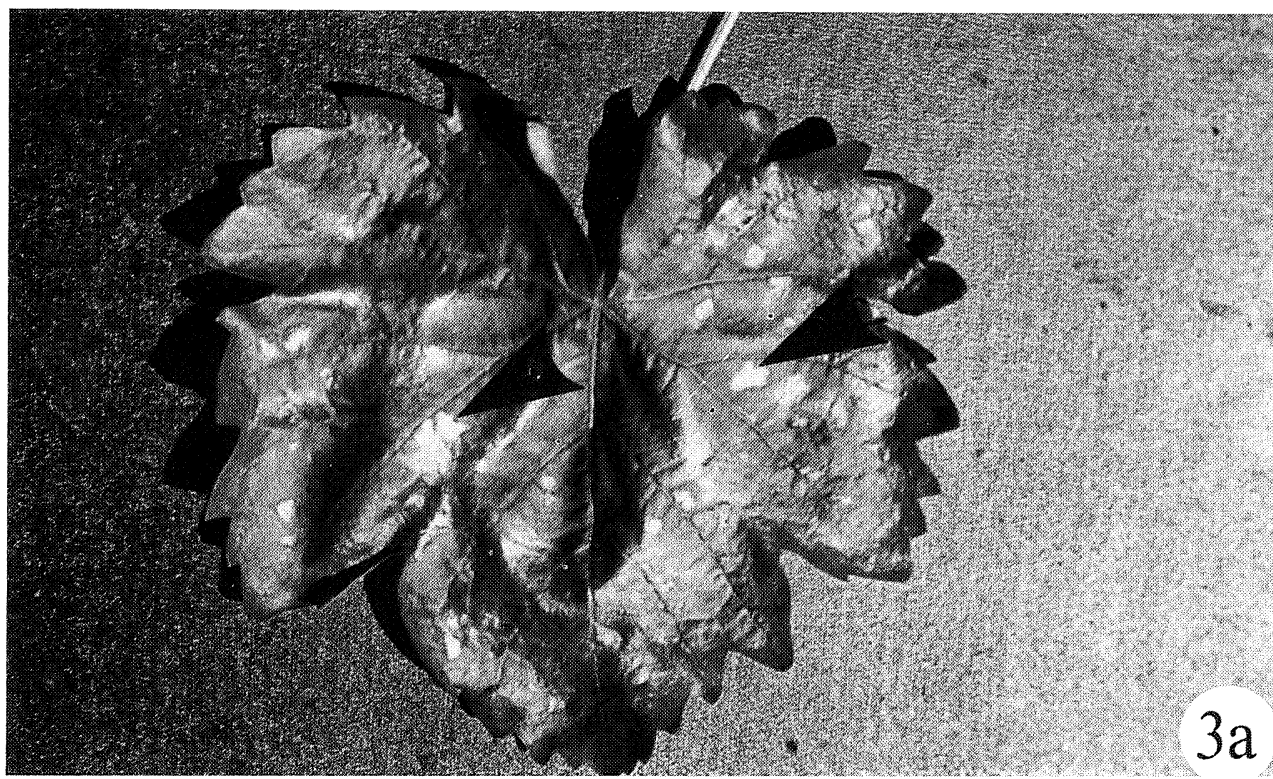

FIG. $3 \mathrm{a}+\mathrm{b}$

Shiny spots (arrows) on (3a) a juvenile light green leaf and on

(3b) dark green leaf of $V$. vinifera var. sultana. (Photos: D.

Saayman).

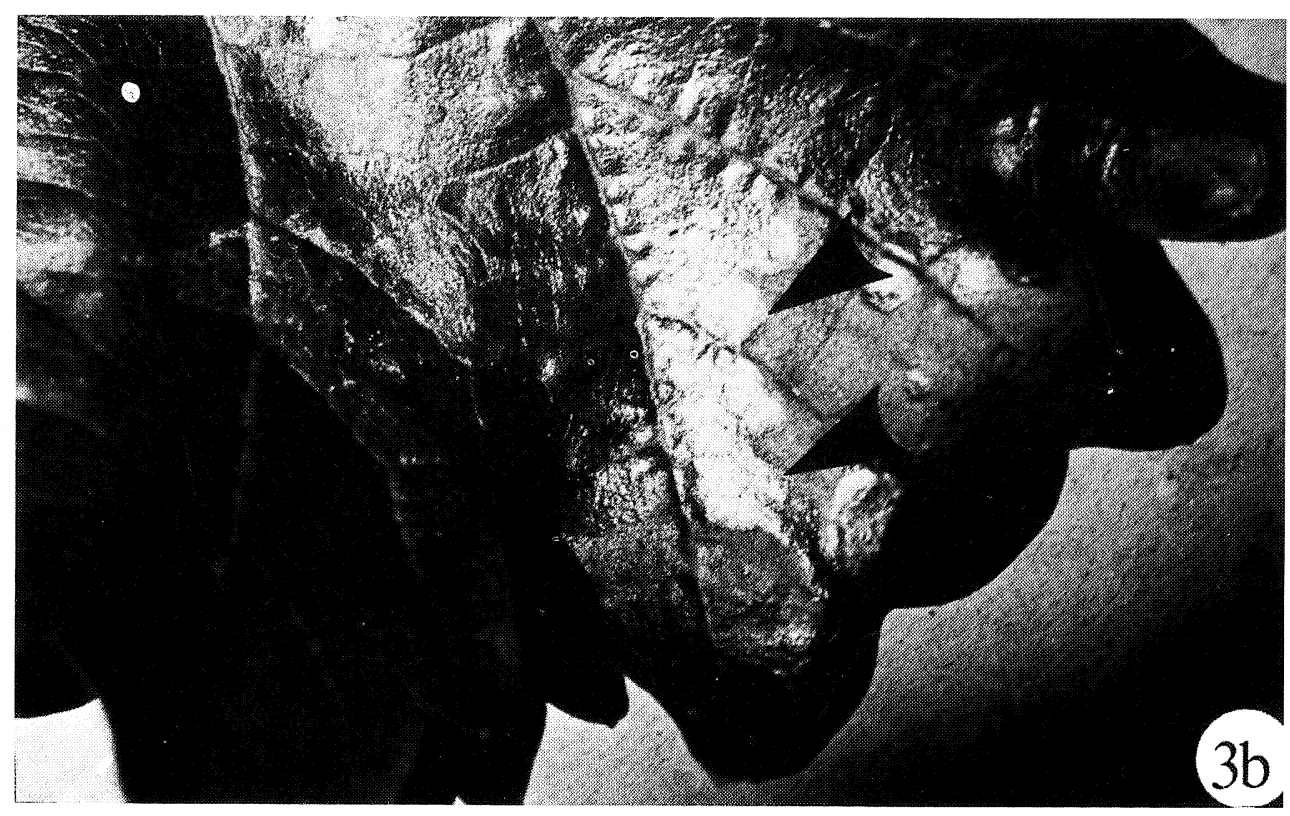

S. Afr. J. Enol. Vitic., Vol. 2. No. 2. 1981 

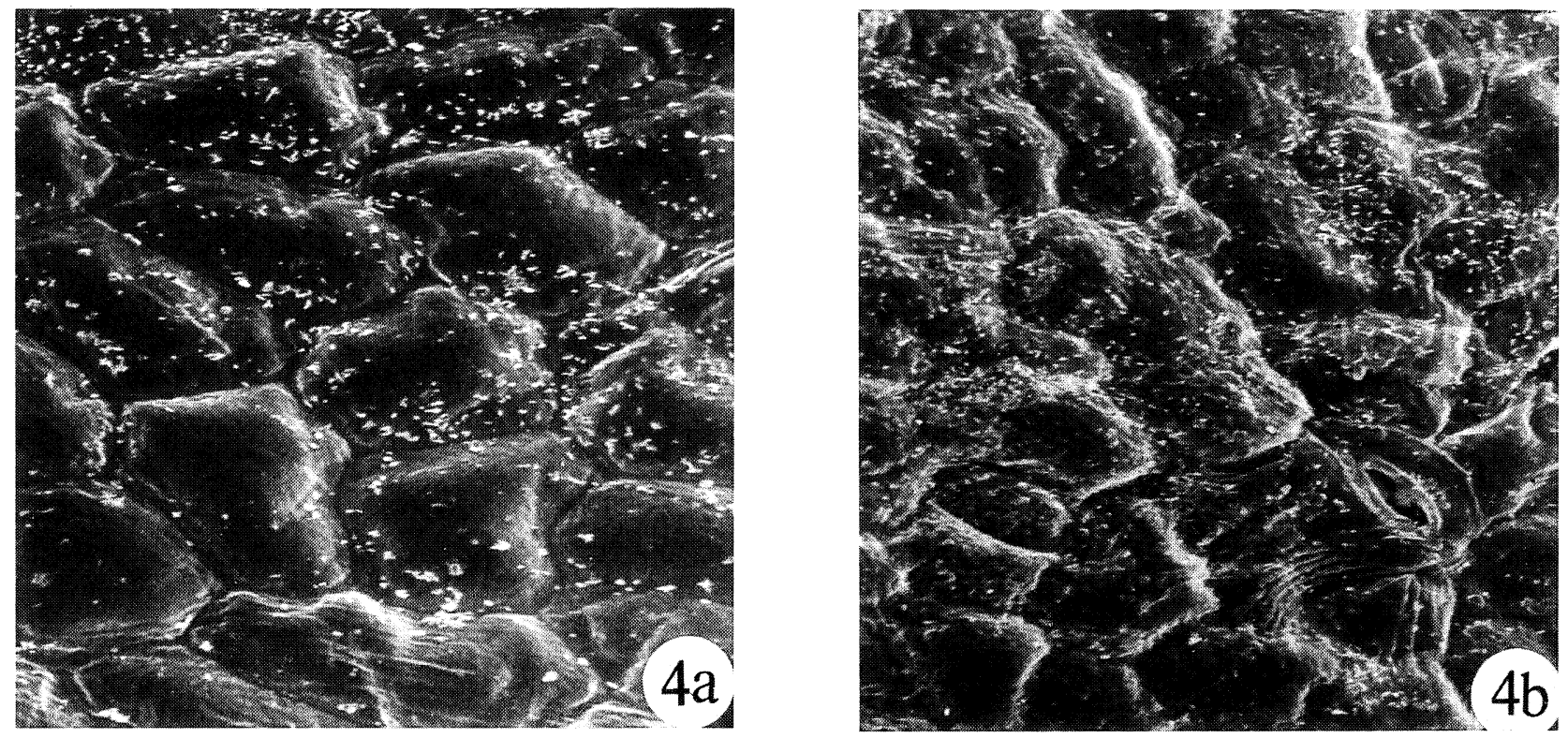

FIG. $4 \mathrm{a}+\mathrm{b}$

Scanning electron micrographs of $(4 a)$ the adaxial leaf surface and (4b) the abaxial leaf surface of a healthy leaf of $V$. vinifera var. sultana (both $\times 975)$.
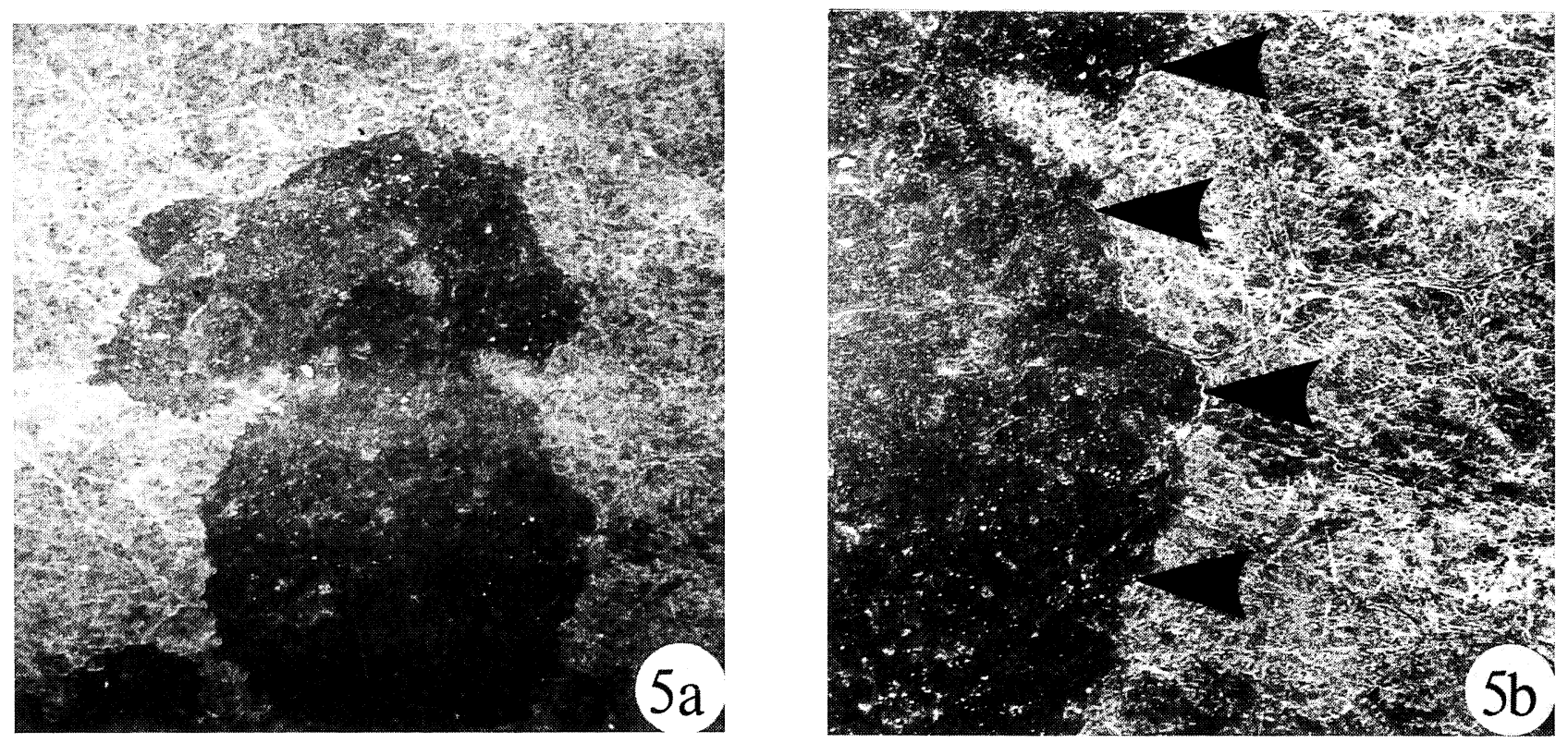

FIG. $5 \mathrm{a}+\mathrm{b}$

Scanning electron micrographs of a G.A.D.-affected leaf of $V$. vinifera var. sultana. $5 \mathrm{a}$; note the collapsed appearance of the epidermis $(\times 20)$ and $(5 b)$ the well defined perimeter of the shiny spot (arrows). $(\times 73)$.

S. Afr. J. Enol. Vitic., Vol. 2. No. 2. 1981 


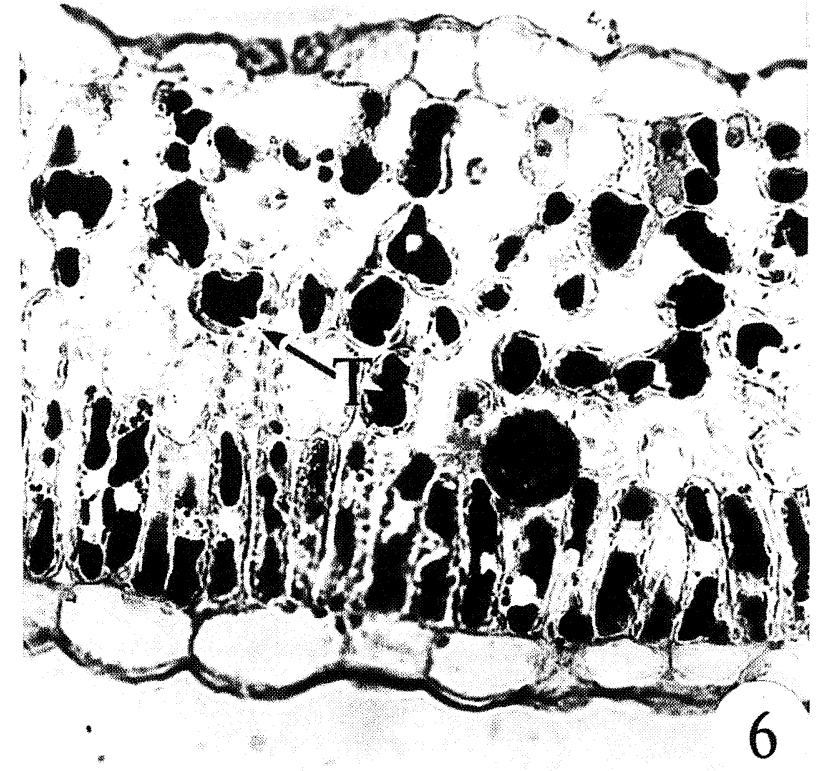

FIG. 6

Light micrograph of a bifacial leaf of $V$. vinifera var. sultana. Note the normal appearance of the adaxial epidermis and the palisade parenchyma. Also note the agranular appearance of the tannins $(\mathrm{T}) .(\times 2800)$.

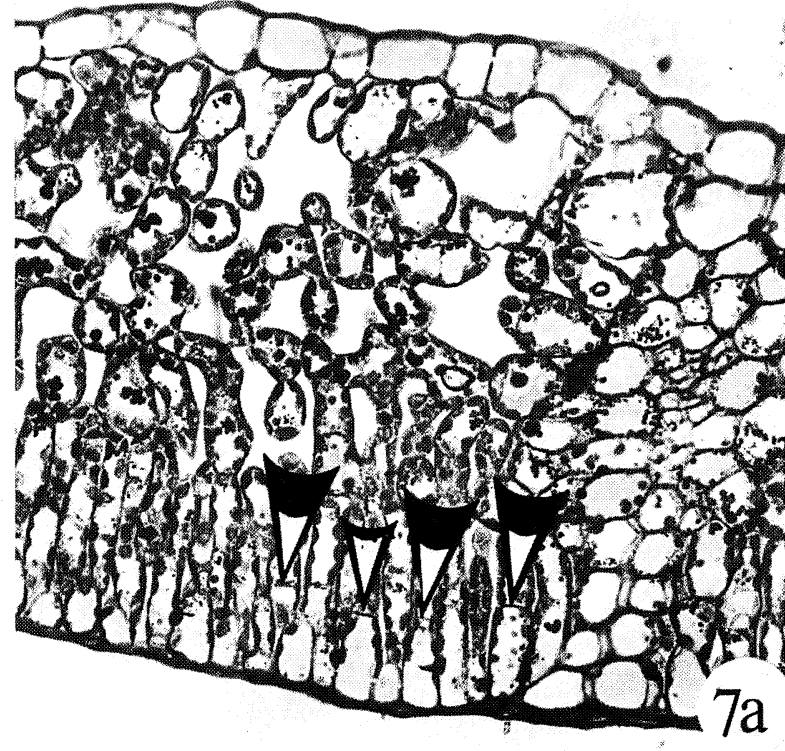

FIg. 7 a, b, c

Light and electron micrographs showing different stages of G.A.D.-affected leaves of $V$. vinifera var. sultana. (7a) Light micrograph of the adaxial epidermis in the process of collapsing. Arrows indicate the formation of septae in the palisade parenchyma $(\times 2800)$. (7b) Electron micrograph of a collapsed epidermal cell wall $(\times 17000)$. (7c) Light micrograph showing the total collapse of the adaxial epidermis at bottom of micrograph. Note that the formation of septae in the palisade parenchyma is well advanced (arrows). ( $\times 3100)$.
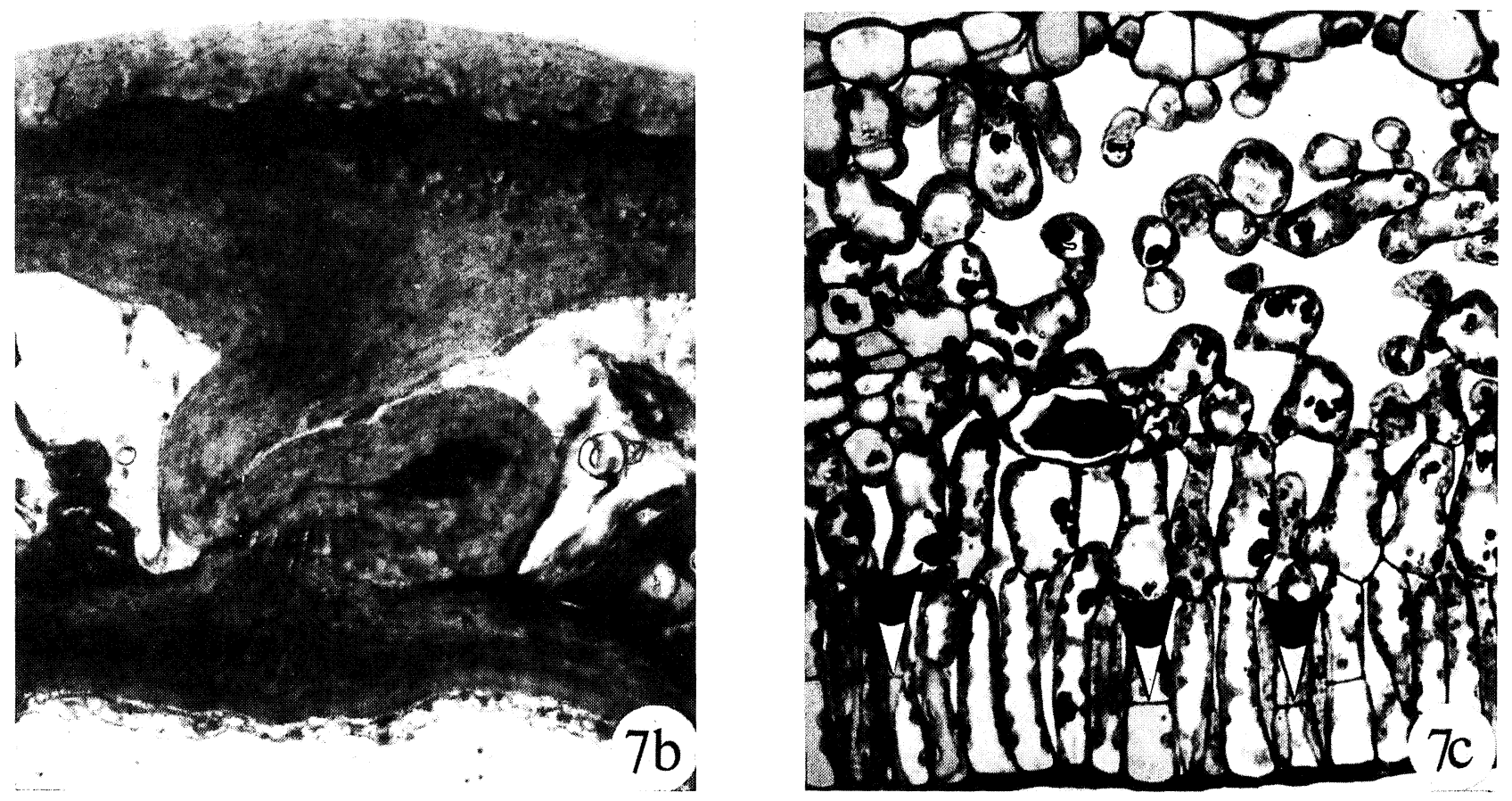

S. Afr. J. Enol. Vitic., Vol. 2. No. 2. 1981 


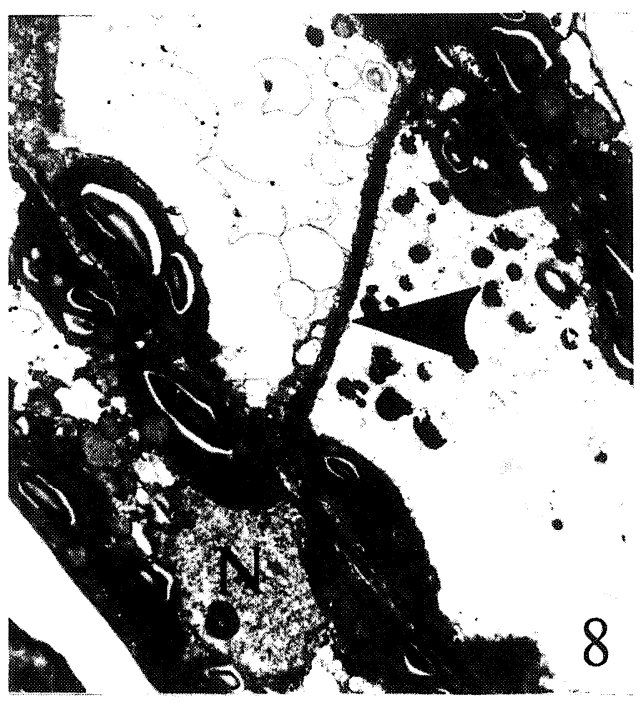

FIG. 8

Electron micrograph showing a septum (arrowhead) in the palisade parenchyma of a G.A.D.-affected leaf of $V$. vinifera var. sultana. Note the granular appearance of the nucleus $(\mathrm{N})$. $(\times 7400)$.

Fig. 10

Electron micrograph of leaf phloem showing the granulated cytoplasm (c), nucleus chromatin (NC), disintegrating membrane (M) and plasmolyses (arrows). (×11 200).

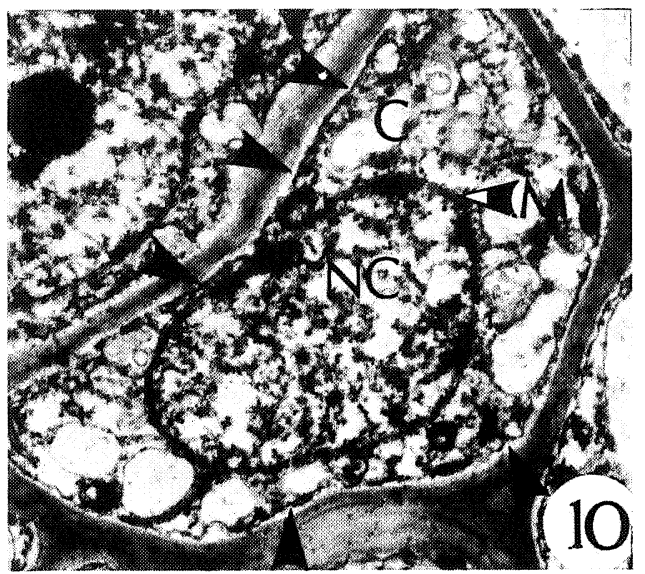

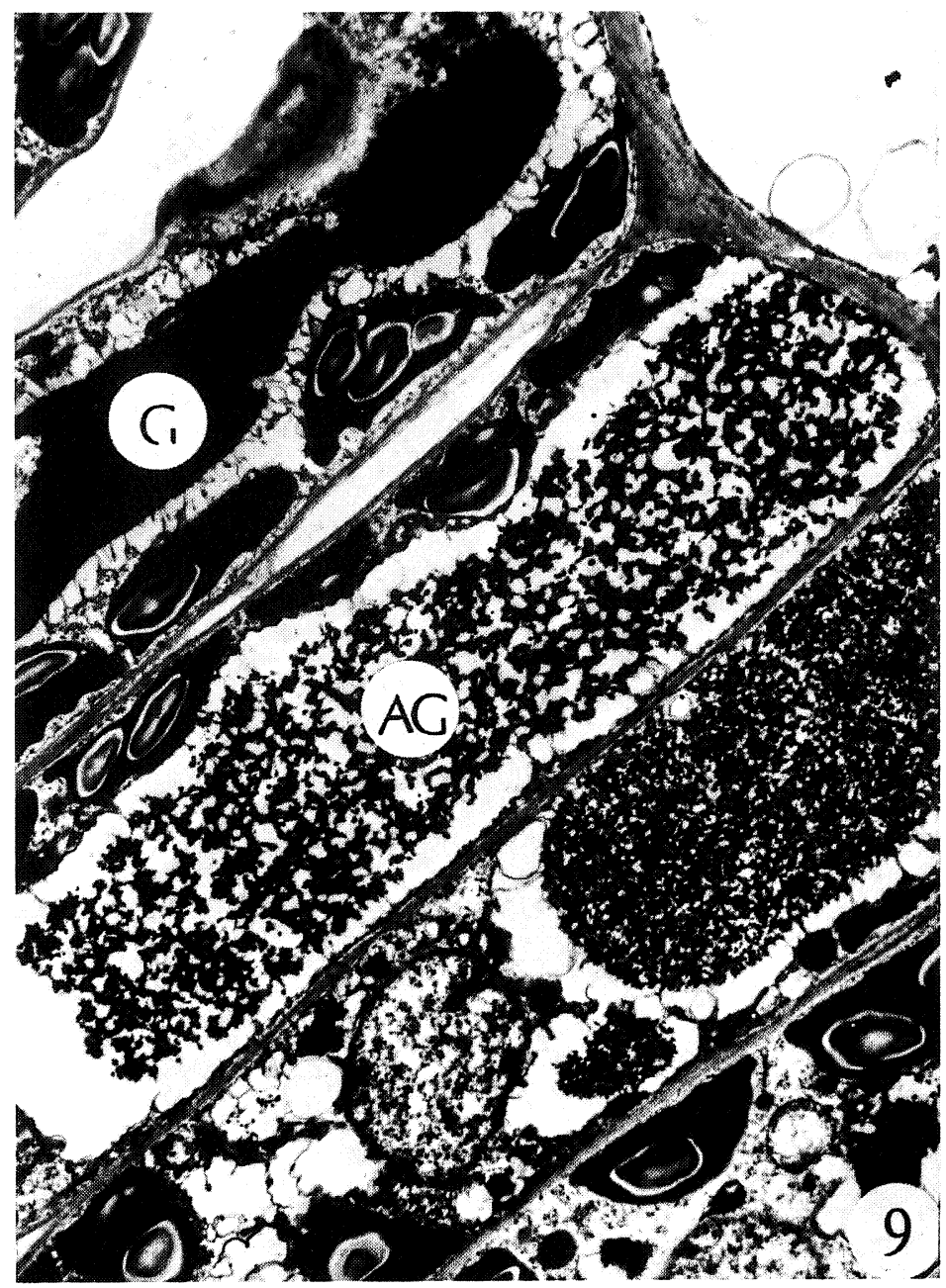

FIG. 9

Electron micrograph showing granular (G) and agranular (AG), tannins in the palisade parenchyma of a G.A.D.-affected leaf of $V$. vinifera var. sultana $(\times 7400)$.

FIG. 11

Light micrograph of a peduncle of a G.A.D.-affected flower cluster of $V$. vinifera var. sultana which did not recover. Arrows indicate peduncle injury $(\times 1400)$.

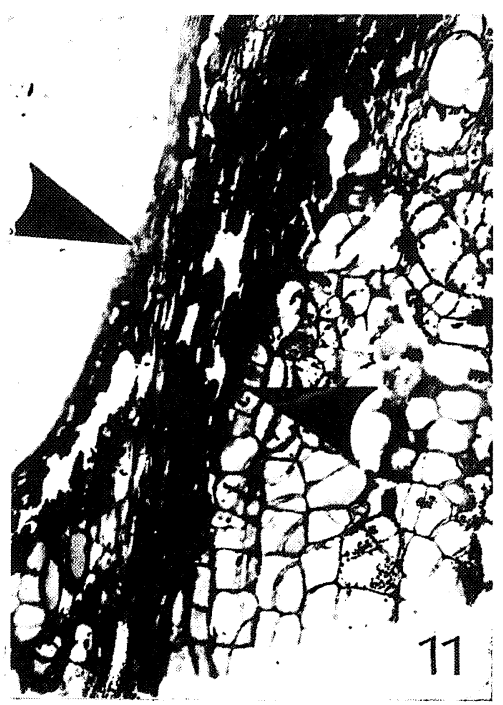

S. Afr. J. Enol. Vitic., Vol. 2. No. 2. 1981 


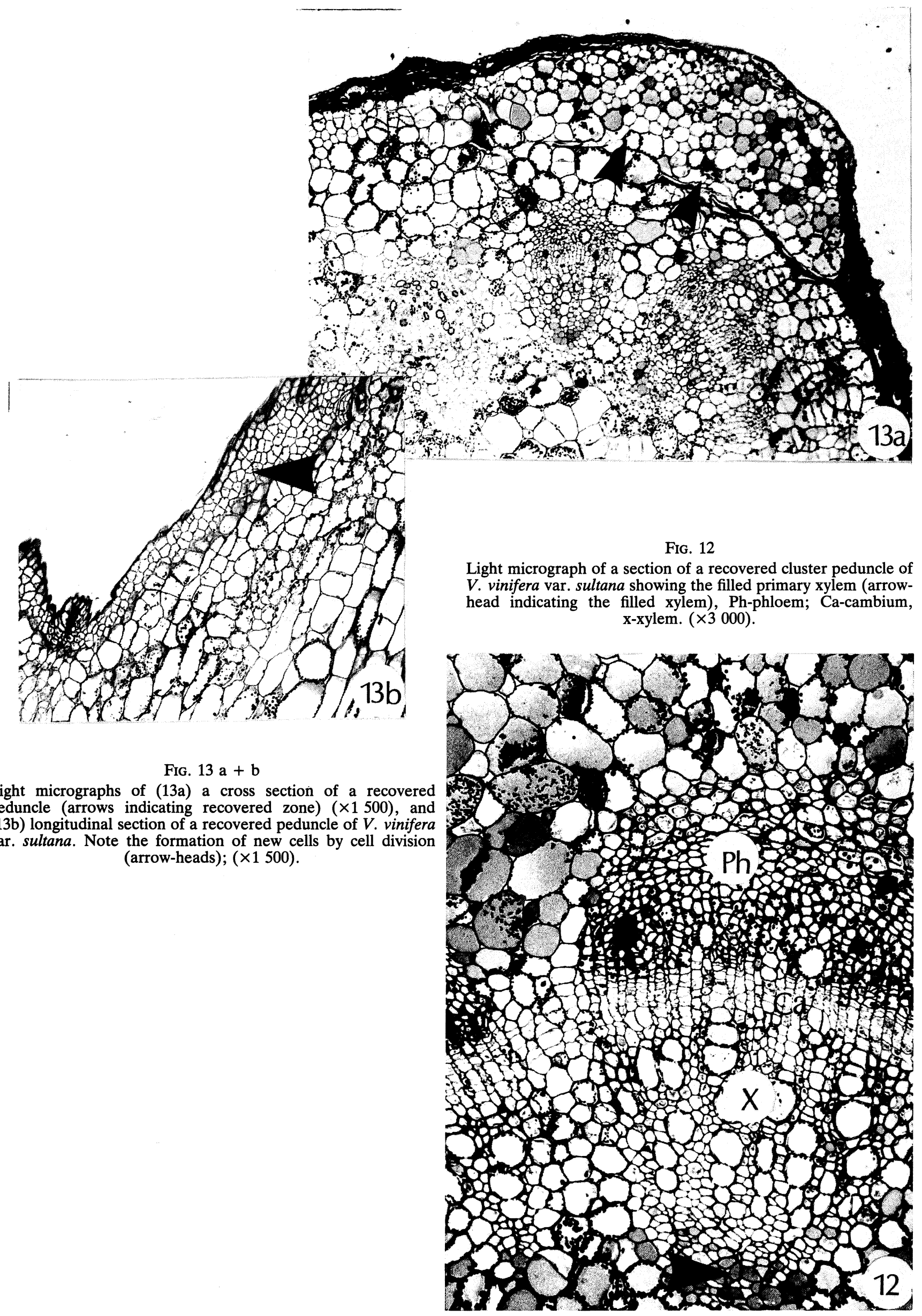

S. Afr. J. Enol. Vitic., Vol. 2. No. 2. 1981 


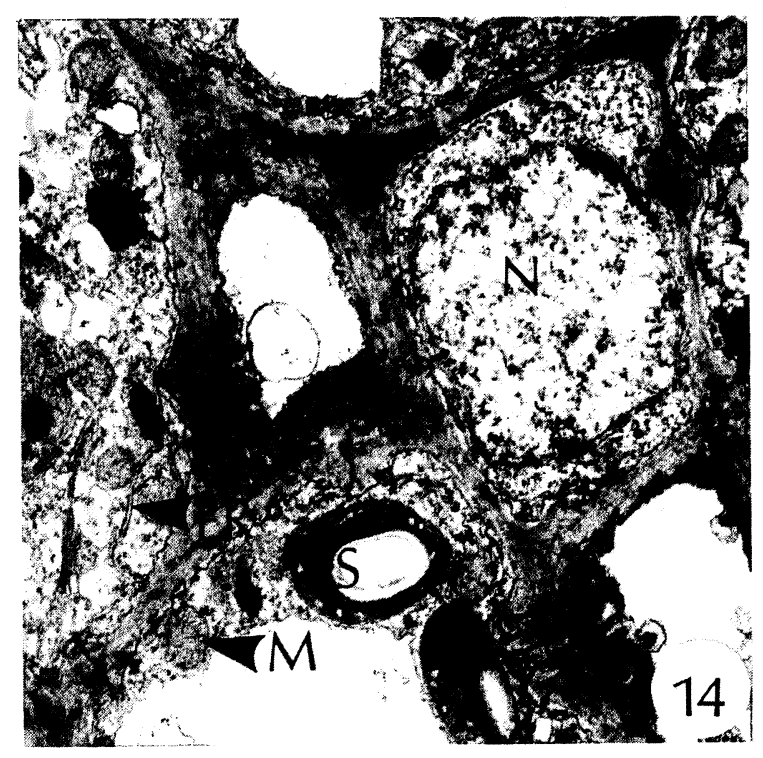

Fig. 14

Electron micrograph of undamaged areas of G.A.D.-affected peduncles of $V$. vinifera var. sultana. The cytoplasm as well as the nucleus have a granular appearance (M-mitochondrion; $\mathrm{N}$-granulated nucleus; ER-endoplasmic reticulum; s-starch). $(\times 11300)$.

\section{LITERATURE CITED}

ALlSOPP, A., 1964. Shoot morphogenesis. Ann. Rev. Pl. Physiol. 15, 225-254.

BARNETT, N. M. \& NAYLOR, A. W., 1966. Amino acid and protein metabolism in Bermuda grass during water stress. Pl. Physiol. 41, 1222-1230.

BOTHA, F. C., 1978. Die invloed van droogtetoestande op die stikstofmetabolisme van twee mielie-lyne. MSc-thesis, University of Potchefstroom.

ESAU, K., 1953. Plant Anatomy. New York: Wiley.

KLIEWER, W. M., 1975. Unpublished report. O.V.R.I., Stellenbosch.

RENA, A. B. \& SPLITTSTOESSER, W. E., 1974. The meta- bolism of proline in cotyledons of pumpkin (Cucurbita moschata). Plant Cell Physiol. 15, 681-686.

REYNOLDS, E. S., 1963. The use of lead citrate at high $\mathrm{pH}$ as an electron opaque stain in electron microscopy. J. Biophys. Biochem. Cytol. 17, 208-212.

SALISBURY, F. B. \& ROSS, W. G., 1978. Plant Physiology. 2nd ed. Wadsworth Publishing Company, Inc., Belmont, California.

SPURR, A. R., 1969. A low-viscosity epoxy resin embedding medium for electron microscopy. J. Ultrastruct. Res. 26, 31-43.

WINKLER, A. J., COOK, J. A., KLIEWER, M. W. \& LIDER, L. A., 1974. General Viticulture. Univ. Calif. Press. Berkeley, Los Angeles, London. 